\title{
Histopathology of human superficial herpes simplex keratitis
}

\author{
P. C. MAUDGAL AND L. MISSOTTEN \\ From the Eye Research Laboratory of the Department of Ophthalmology. \\ Catholic University of Leuven, Belgium
}

SUMMARY In-vivo corneal replicas were made in 20 cases of patients with superficial dendritic ulcers of the cornea. Histopathological study of the replicas and superficial epithelial cells showed that the dendrites are composed of rounded epithelial cells and variable sized syncytia containing bizarre shaped nuclei. Pseudopodia-like processes containing DNA and some RNA extend from the syncytia into the surrounding epithelial cells, which on coming into contact with these processes :become rounded and liquefied to give rise to another syncytium. The epithelial cells adjacent to the $\vec{\sigma}$ dendrite are elongated and usually orientated parallel to the long axis of the lesion. Surrounding $ᄋ$ the terminal bulbs, they are disposed in an arcuate fashion. These cells show C-mitotic lesions, intranuclear and cytoplasmic inclusion bodies, and polykaryocyte formation. Microscopic examination of the corneal replicas shows the intranuclear lesions and rounding of cells up to about $2 \mathrm{~mm}$ away from the dendritic ulcers. These areas appear normal on clinical examination.

The corneal scrapings of herpetic dendritic ulcers have been studied by Thygeson (1958) and Naib et al. (1967). These authors have described the giant polykaryocytes in the scrapings to be characteristic of herpes simplex keratitis. As the scrapings destroy the exact histological detail owing to the crumpling of cells this method does not provide a full histological picture. We have developed an in-vivo corneal replica technique to study the histopathology of superficial keratitis (Maudgal, 1976; Maudgal and Missotten, 1977; Missotten and Maudgal, 1977).

With this technique we have been able to study the replication and maturation stages of the herpes virus and the formation of disseminating inclusion bodies in experimental herpes simplex keratitis in rabbits (Maudgal, 1976). In this paper we report the histopathology of human superficial dendritic lesions studied by the in-vivo corneal replica technique.

\section{Subjects and methods}

In-vivo collodion corneal replicas were made in 20 patients diagnosed clinically to have superficial herpetic dendritic keratitis in 1 eye. The technique of making a corneal replica in vivo and preparing flat mounts has been described previously (Missotten

Address for reprints: Professor L. Missotten, Oogziekten, A.Z. St. Rafaël, Kapucijnenvoer 7, 3000 Leuven, Belgium and Maudgal, 1977). The replicas were examined by phase-contrast microscopy. After dissolving the collodion membrane in acetone the flat mounts of superficial epithelial cells were studied by phasecontrast and oblique-illumination microscopy. Later the flat mounts were stained by haematoxylin and eosin, acridine orange, and Love's toluidine blue ammonium molybdate (TBM) method (Pearse, 1968) and studied by light microscopy.

\section{Results}

Phase-contrast microscopy of the replicas and the 3 flat mounts of superficial epithelial cells shows that $\delta$ the dendritic ulcers (Fig. 1) are made up of different $₹$ sized rounded epithelial cells many of which form 0 varying sized syncytia (Figs. 2, 3, 4). The nodular areas in the dendrites and the terminal bulbs of the finger-like projections contain larger syncytia and $\mathrm{a}$ larger number of rounded cells.

Our observations under oblique-illumination $\tilde{\sim}$ microscopy of unstained specimens and the light $\underset{\omega}{N}$ microscopy of stained preparations suggest that the syncytia are produced by fusion of cells. At the borders of the syncytium partly fused cells are seen $\frac{\Phi}{\Phi}$ (Figs. 3, 4). Bizarre shaped nuclei are present in the $\stackrel{\mathcal{O}}{+}$ syncytial masses. Most of them are small and 0 rounded or irregular and elongated. In the haema- 0 toxylin-eosin stained flat mounts the nuclei are $\stackrel{\mathbb{D}}{\stackrel{D}{\circ}}$ represented by faint basophilic masses in some parts $\stackrel{\mathbb{Q}}{\Omega}$ 
of the syncytia where nuclear outlines cannot be seen (Fig. 5).

TBM staining and the acridine orange staining show the dispersal of nuclear DNA into the cytoplasm from these nuclei. In other areas increase in the size of nuclei (Fig. 6), granular changes in the nuclei, and intranuclear inclusions may be seen (Fig. 7). The intranuclear inclusions are basophilic and are usually surrounded by an area of rarefaction of the nucleoplasm. Sometimes clumping and fragmentation of the nuclear chromatin are seen. Nuclear fragments may be found scattered in the syncytial masses. Similar lesions may be seen in the nuclei of rounded cells, which are quite often very large.

The rounded epithelial cells and the liquefying cells possess variable amount of cytoplasm. It may be present only in the form of a marginal strip

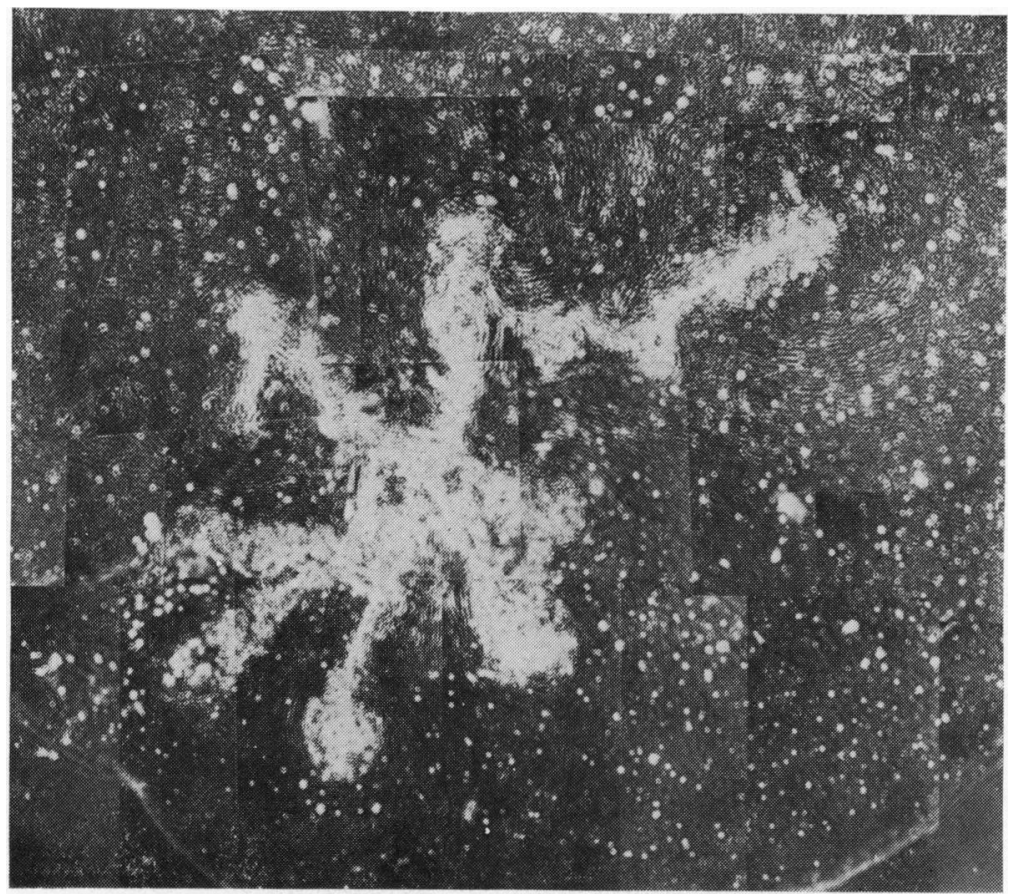

Fig. 1 Photo-montage of a corneal replica from a patient having typical dendritic ulcer. Nodes and terminal bulbs are evident. Note the elongated cells surrounding the lesion. Bright circular dots are artefacts. Phase-contrast microscopy, obj. $(\times 10)$

Fig. 2 Part of a dendritic ulcer showing syncytia and rounded epithelial cells in the lesion. Elongated cells are arranged in an arcuate fashion round the terminal bulbs and fill the spaces between the finger-like projections. Phase-contrast microscopy of the replica $(\times 133)$

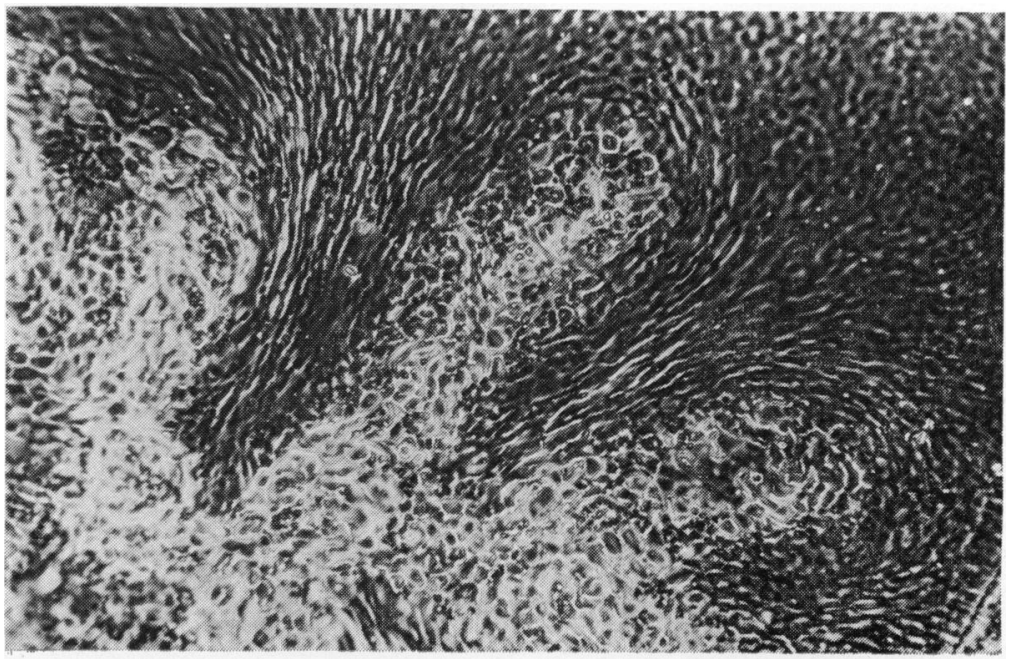




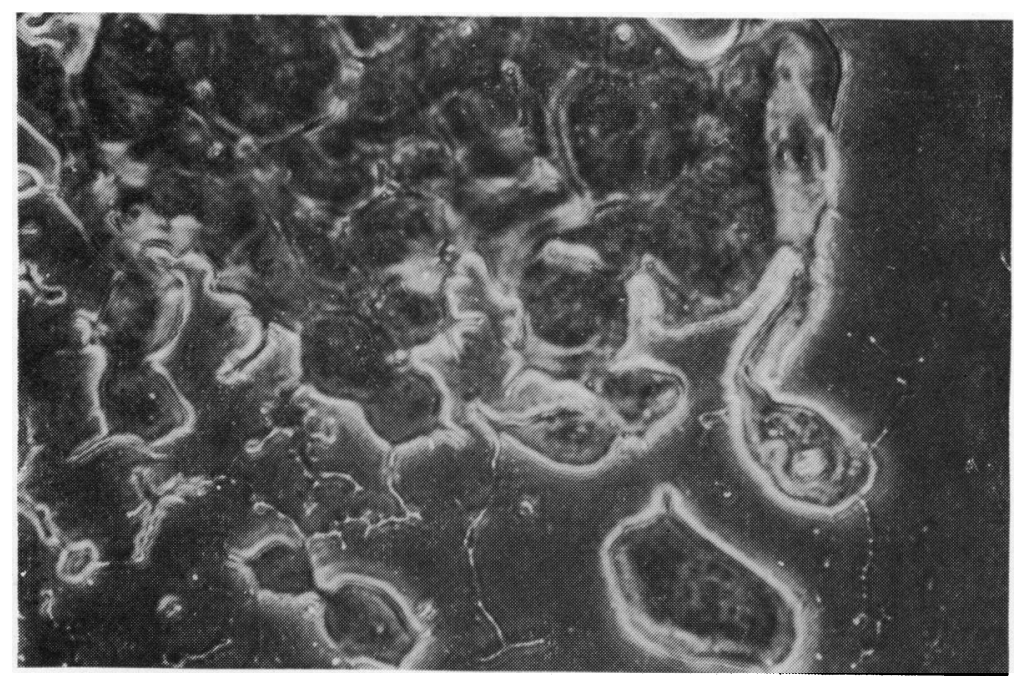

Fig. 4 Partly fuset rounded epithelial cells are seen at the margin of a syncytium in a dendritic ulcer.

Oblique-illumination microscopy $(\times 390)$
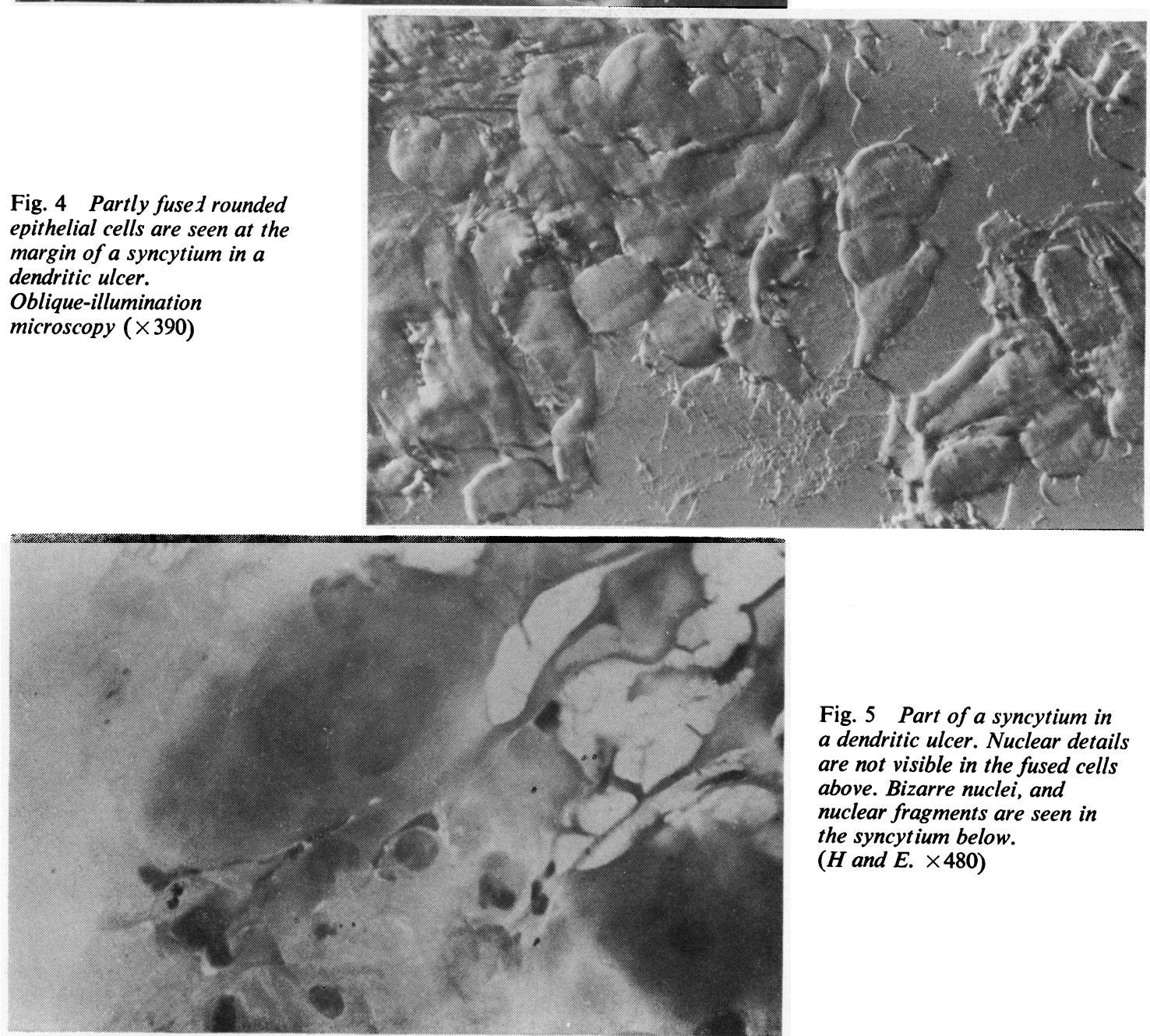

Fig. 3 Part of a syncytium in a dendritic ulcer. At the margin of the syncytium partly fused and rounded epithelial cells are seen. Note the pseudopodia-like processes extending from the syncytium to some cells.

Phase-contrast microscopy $(\times 400)$

Fig. 5 Part of a syncytium in a dendritic ulcer. Nuclear details are not visible in the fused cells above. Bizarre nuclei, and nuclear fragments are seen in the syncytium below. ( $H$ and $E . \times 480)$ 
Fig. 6 Part of a syncytium in a dendritic ulcer. Large cells with large nuclei are seen. Note clumping and rarefaction of nuclear chromatin in some nuclei. Some nuclear fragments are lying in the syncytium. $(H$ and $E . \times 480)$

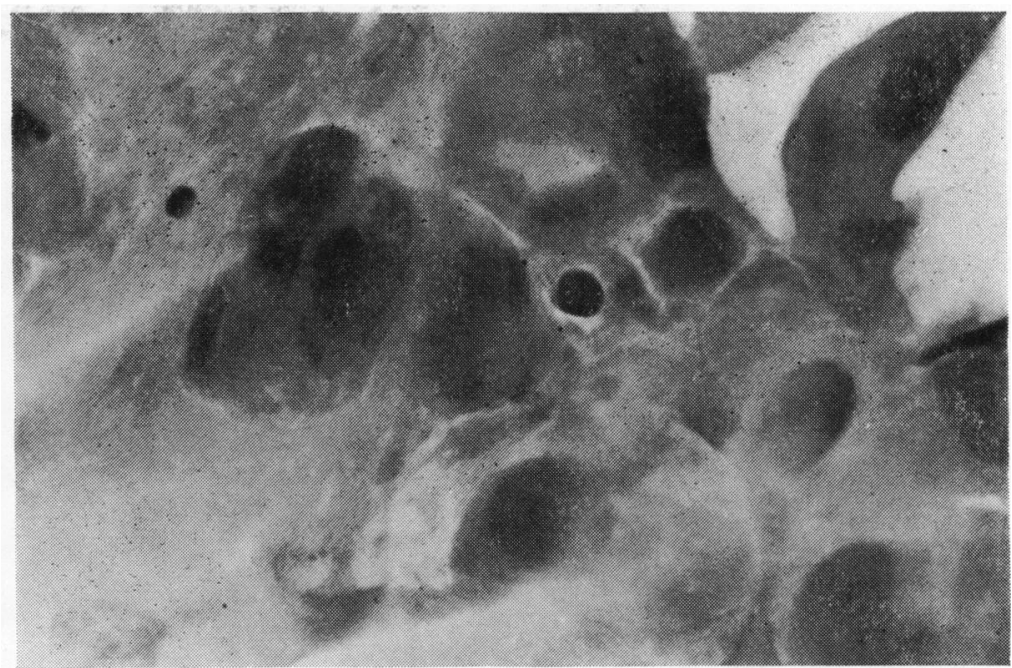

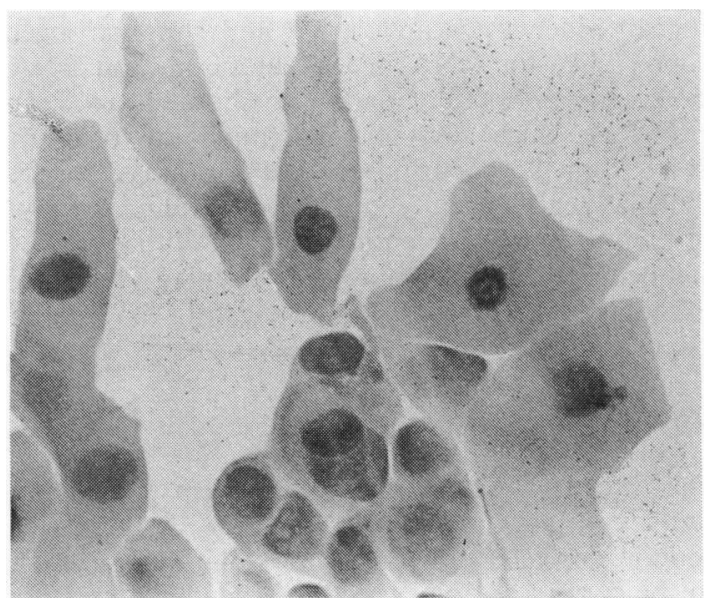

Fig. 7 A large epithelial cell (upper right) showing intranuclear inclusion. Central dense area of clumped chromatin is surrounded by a ring of rarefaction.

The elongated cell (upper middle) shows granular change in the nucleus and is connected by $a$ pseudopodia-like process to the small syncytium below. Some rounded cells are also seen. $(H$ and $E . \times 395)$

round the nuclei or on the contrary in very large amount, quite out of proportion to the size of the nucleus (Figs. 8, 9). The acridine orange staining shows an increase in the quantity of RNA in the cytoplasm of these cells as compared to the peripheral normal cells. The presence of green fluorescence of DNA is often encountered in the cytoplasm.

In the areas of necrosis the cytoplasm may be totally lost where faintly stained and deformed or fragmented nuclei are seen in the debris (Fig. 9).
Sometimes rounded ghost cells are seen in the debris (Fig. 10). They contain strongly eosinophilic cytoplasm and basophilic stellate nuclear material in the centre. In the area of necrosis vacuolation of the cytoplasm is frequently seen.

From the rounded cells and syncytia pseudopodialike processes are seen extending towards the surrounding cells (Figs. 3, 4, 7, 9) which are in contact with other rounded cells. In some areas such rounded cells have also become liquefied and partly or wholly fused to form a syncytium. The pseudopodia-like processes may be very thin and may extend across a few cells before contacting another

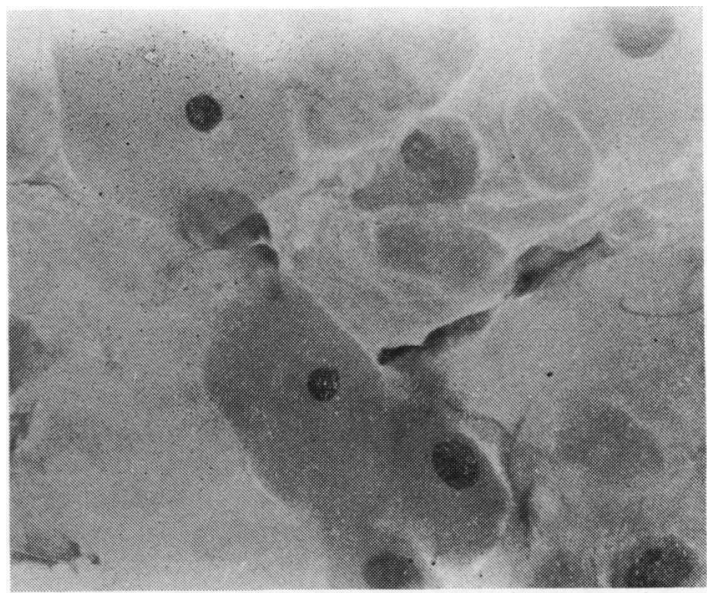

Fig. 8 Two large cells containing small nuclei at the border of a syncytium. The rounded epithelial cell below and to the right shows intranuclear granules. $(H$ and $E . \times 390)$ 


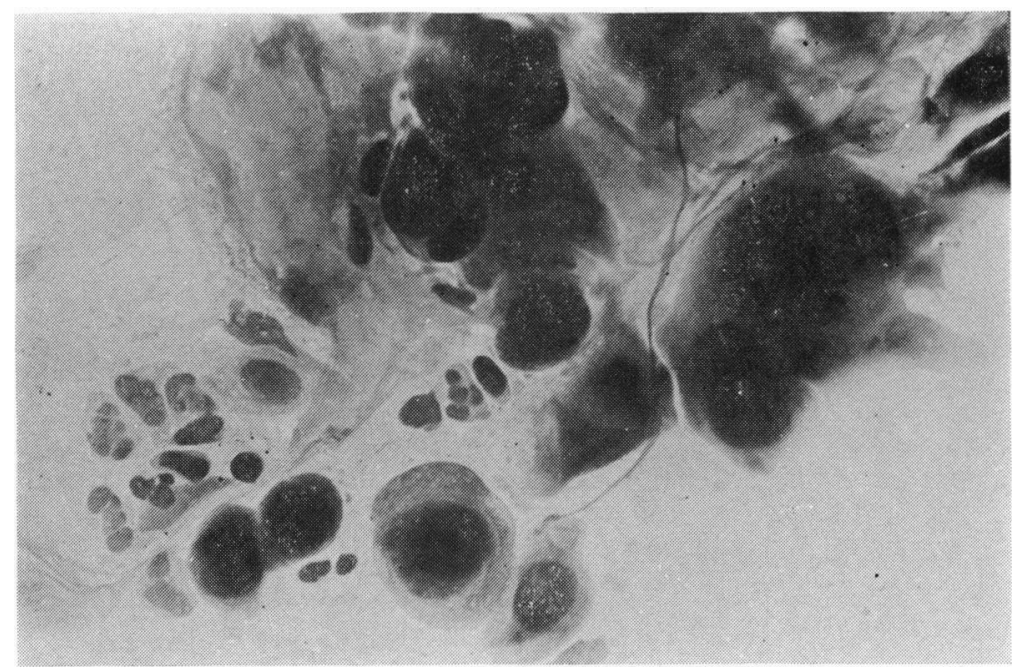

Fig. 9 Pseudopodia-like processes extending from the syncytial mass above (partly shown) to the 2 rounded epithelial cells below. Some of the rounded cells contain scanty cytoplasm. To the left is an area of necrosis. ( $H$ and $E . \times 470)$

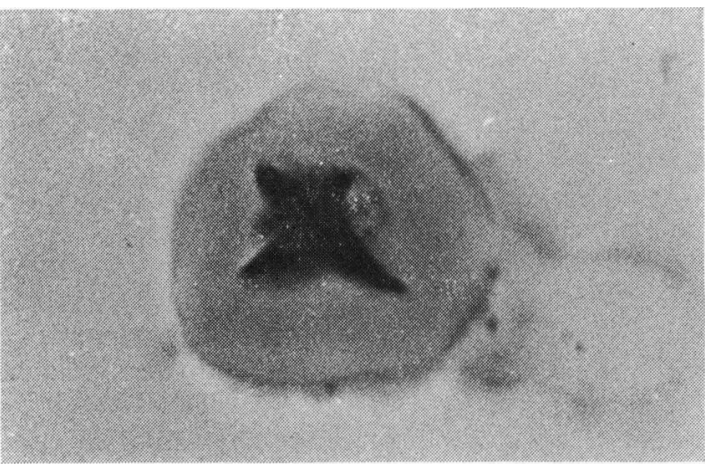

Fig. 10 A ghost cell showing stellate nucleus. $(H$ and $E . \times 1130)$

cell at their tip. They contain RNA and DNA as seen by acridine orange staining. The 3 to 4 rows of the epithelial cells immediately adjacent to the dendritic lesion are elongated and orientated parallel to the lesion. The area between the 2 finger-like processes may be occupied by such elongated cells (Figs. 1, 2). Around the terminal bulb these cells are disposed in an arcuate fashion. Some of these cells show liquefaction and rounding. In these cells C-mitotic lesions (Fig. 11) and intranuclear inclusions may be seen. Fusion of the cells is often present. The fusing cells may possess elongated nuclei, which are displaced towards the area of contact.

The cytoplasmic inclusions (Fig. 12) are often situated near to the nuclei. They are faintly eosinophilic rounded areas containing basophilic granules. The epithelial cells peripheral to the elongated cells appear oedematous and larger and show stronger fluorescence for RNA in the cytoplasm and DNA in the nuclei. Some of them also show intranuclear inclusions. Such cells may be found up to $2 \mathrm{~mm}$ away from the dendritic ulcer. These areas do not show any abnormality on clinical biomicroscopy. In the replicas of the patients having diffuse epithelial oedema but no fluorescein staining clinically, rounding and liquefication of the cells is seen in extensive areas.

\section{Discussion}

The human dendritic corneal ulcers of herpes simplex origin have been clinically described to contain swollen epithelial cells (Duke-Elder, 1965). In the corneal scrapings from the dendritic keratitis giant polynucleate cells have been described (Thygeson, 1958; Naib et al., 1967). Rounding of the epithelial cells and their degeneration and clumping of the nuclear chromatin have been reported by Hudson et al. (1976) in experimental herpes keratitis.

Our investigation shows that the dendritic lesions are made up of variable sized syncytia and rounded epithelial cells. The syncytia are formed by the fusion of rounded and liquefied cells. It may be speculated that the giant polykaryocytes described by Thygeson (1958) and Naib et al. (1967) could be parts of such syncytia broken down during the scraping or preparation of the slide. The granular particles seen in the nuclei of some cells resemble the A granules or maturing virus particles described by Love and Wildy (1963) and demonstrated in experimental herpes simplex keratitis in rabbits by 
Maudgal (1976). The presence of green fluorescence for DNA in the cytoplasm of some cells may be related to the release of these virus particles into the cytoplasm.

The degenerating cells contain either swollen or small deformed nuclei. The nuclei in the syncytia are bizarre shaped. The nuclear chromatin may be clumped or fragmented. Fragments of the nuclear material may be found scattered in the syncytial masses. It is not possible to confirm if these nuclear fragments contain virus particles. Balloon degeneration of the nuclei was not seen, although many rounded cells contain swollen nuclei. The cells adjacent to the syncytia may show intranuclear $\mathrm{C}$-mitotic lesion or a colchicine-like effect, demon- strated by Love and Wildy (1963) in HeLa cell cultures infected by the herpes simplex virus. However, as the superficial epithelial cells are at the stage of being shed off and relatively metabolically inactive, this lesion is only infrequently seen. The basophilic granules in the cytoplasmic inclusions may be the maturing virus particles.

The acridine orange staining shows an increase in the cytoplasmic RNA and nuclear DNA in the epithelial cells. It is known that in a productive infection with the herpes viruses the synthesis of cell-specific proteins ceases and virus-specific proteins are synthesised (Kaplan et al., 1975). The increase in the ribonucleoproteins could be due to the stimulation of the cell activity by the virus.

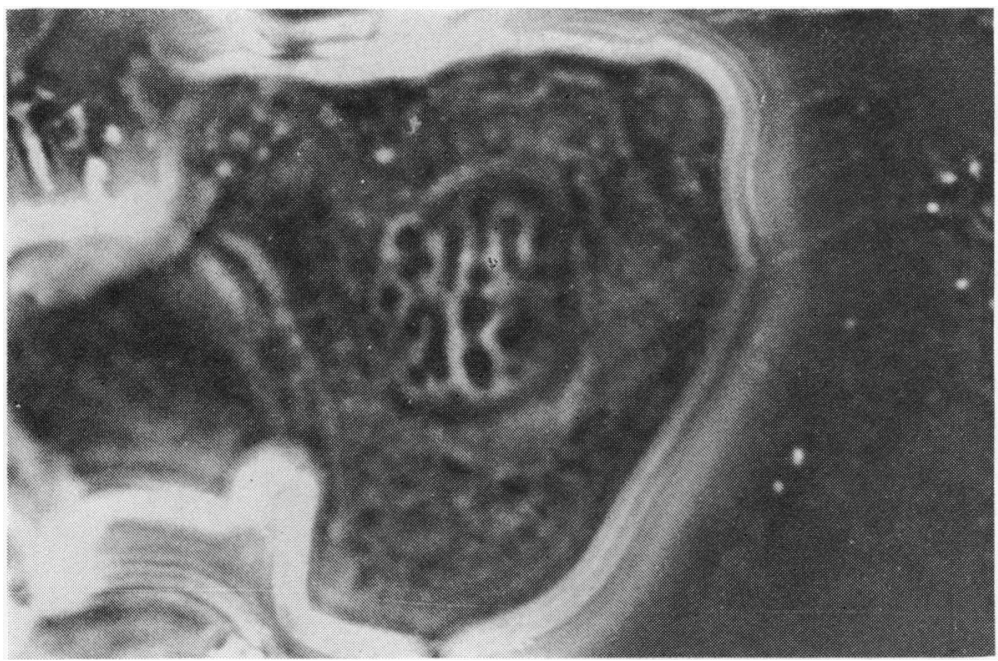

Fig. 11 An epithelial cell adjacent to the syncytium showing C-mitotic intranuclear lesion. Phase-contrast microscopy $(\times 1200)$

Fig. 12 Cytoplasmic inclusion seen in an elongated epithelial cell surrounding the dendritic ulcer. $H$ and $E$ stain $(\times 970)$

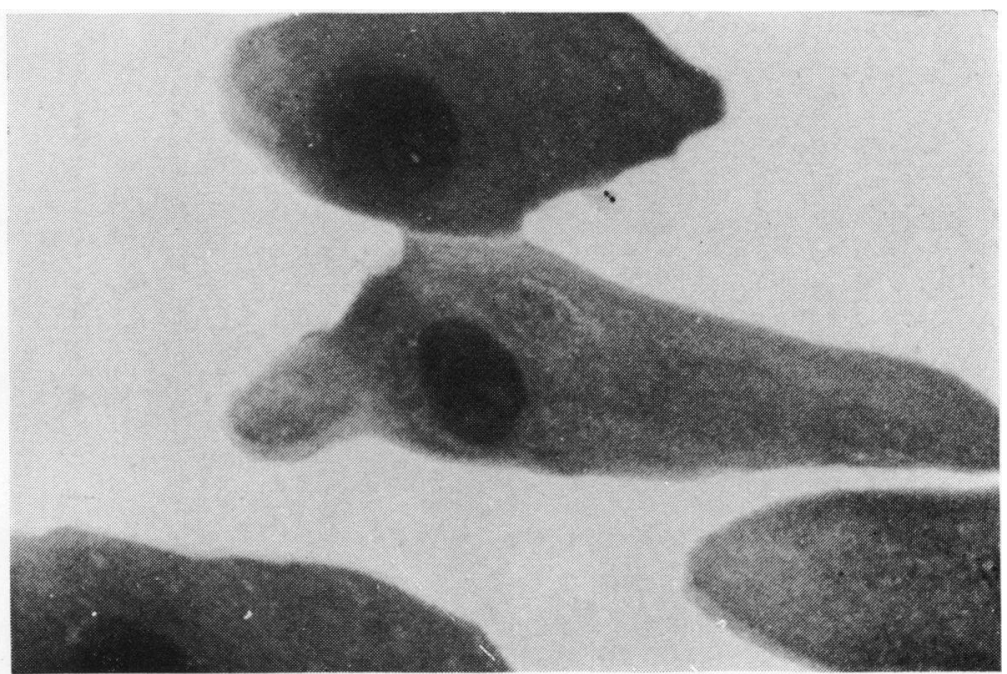


The superficial epithelial cells surrounding the dendritic lesions are elongated and orientated parallel to the long axis of the lesion and in an arcuate pattern around the terminal bulbs. Their shape and arrangement may be due to the mechanical effect of displacement by the large masses of syncytia and swollen rounded cells. Scattered pathological cells may be found about $2 \mathrm{~mm}$ away from the dendrites. Larger areas of involvement are seen in the cases showing epithelial oedema. It is interesting to note that such areas do not stain with fluorescein and appear clinically normal. Lack of leucocytes in the replica specimens is noteworthy. Some rounded cells of lymphocyte size are seen, but their staining characteristics and cytological details show that they are degenerating rounded epithelial cells.

\section{References}

Duke-Elder, S. (1965). System of Ophthalmology, Vol. 8, Diseases of the outer eye. Kimpton: London.

Hudson, J. B., Hollenberg, M. J., Wilkie, J. S., and Lewis,
B. J. (1976). Ultra structural study of lesions induced in rabbit cornea by herpes simplex virus 1 and 2 . Journal of Infectious Diseases, 133, 367-381.

Kaplan, A. S., Erickson, J. S., and Ben-Porat, T. (1975). Excretion of specific glycoproteins by cells infected with herpes simplex virus, Types 1 and 2. Progress in Medical Virology, 21, 1-12.

Love, R., and Wildy, P. (1963). Cytochemical studies of nucleo-proteins of $\mathrm{HeLa}$ cells infected with herpes virus. Journal of Cell Biology, 17, 237-254.

Maudgal, P. C. (1976). The epithelial response in keratitis sicca and keratitis herpetica (an experimental and clinical study). Thesis for D.Sc. (Ophth.), University of Louvain.

Maudgal, P. C., and Missotten, L. (1977). The corneal replica technique. Read before the Belgian Society of Ophthalmology, February (in press).

Missotten, L., and Maudgal, P. C. (1977). The corneal replica technique used to study the superficial corneal epithelium in vivo. American Journal of Ophthalmology, 84, 104-111.

Naib, Z., Clepper, A., and Elliot, S. (1967). Exfoliative cytology as an aid in the diagnosis of ophthalmic lesions. Acta cytologica, 11, 295-303.

Pearse, G. A. E. (1968). Histochemistry: Theoretical and Applied, Part I. Churchill Livingstone: Edinburgh.

Thygeson, P. (1958). Cytological observations on herpetic keratitis. American Journal of Ophthalmology, 45, 240-245. 